\title{
Enhanced Interphase Adhesion and Anticorrosion Properties in Epoxy Coating Modified via Acrylic Resin
}

\author{
Kai Wan ${ }^{1,}$, Jiarun $\mathrm{Li}^{1,2}$, Weichen $\mathrm{Xu}^{1}$, Liangmin $\mathrm{Yu}^{3,}{ }^{*}$, Baorong Hou ${ }^{1}$, Min Liu $^{4}$ \\ ${ }^{1}$ Key Laboratory of Marine Environmental Corrosion and Bio-fouling, Institute of Oceanology, \\ Chinese Academy of Sciences, Qingdao 266071, Shandong, China; \\ ${ }^{2}$ University of Chinese Academy of Sciences, Beijing 100049, China \\ ${ }^{3}$ Key Laboratory of Marine Chemistry Theory and Technology, Ministry of Education, Ocean \\ University of China, Qingdao 266100, Shandong, China; \\ ${ }^{4}$ Electric Power Research Institute, Zhejiang Power Corporation, State Grid Corporation of China, \\ Hangzhou, 310000, Zhejiang, China \\ *E-mail: wank@qdio.ac.cn, yuyan@ouc.edu.cn
}

doi: $10.20964 / 2016.11 .06$

Received: 20 July 2016 / Accepted: 3 September 2016 / Published: 10 October 2016

Poly ( $\alpha$-methyl methacrylate-butyl acrylate-glycidyl methacrylate) (PMBG) and poly ( $\alpha$-methyl methacrylate-butyl acrylate) (PMB) were synthesized via solution polymerization and characterized via Fourier transform infrared spectroscopy (FTIR). And then, the modified epoxy coatings were prepared through dispersing 4 wt.\% of PMBG and PMB in an epoxy coating through physical blending, respectively. The coatings were painted on the mild steel substrates and their anticorrosion performances were characterized by salt spray test and electrochemical impedance spectroscopy (EIS). Interphase adhesion was characterized by pull-off test. Incorporation of $4 \mathrm{wt} \%$ of acrylic resin, especially PMB (as a constituent of the resin), into the epoxy coating significantly enhanced the anticorrosion performance and interphase adhesion of the coating (45\%) through improving their inner structure.

Keywords: Organic coatings; Corrosion resistance; Interphase adhesion; Salt spray test; EIS

\section{FULL TEXT}

(C) 2016 The Authors. Published by ESG (www.electrochemsci.org). This article is an open access article distributed under the terms and conditions of the Creative Commons Attribution license (http://creativecommons.org/licenses/by/4.0/). 